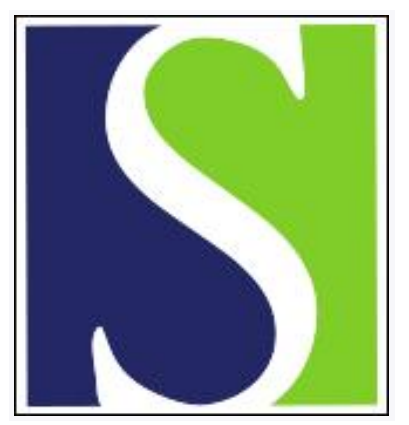

Scand J Work Environ Health 2006;32(2):154-159

https://doi.org/10.5271/sjweh.991

Issue date: 30 Apr 2006

Hemoglobin adducts in the assessment of potential occupational exposure to acrylamides-three case studies by Paulsson B, Larsen K-O, Törnqvist M

Affiliation: Department of Environmental Chemistry, Stockholm University, S-106 91 Stockholm, Sweden. margareta.tornqvist@mk.su.se

Refers to the following text of the Journal: 2001;27(4):219-226

Key terms: acrylamide; case report; hemoglobin adducts; in vivo dose monitoring; N-methylolacrylamide; neurotoxic symptom; occupational exposure; sealing product

This article in PubMed: www.ncbi.nlm.nih.gov/pubmed/16680386

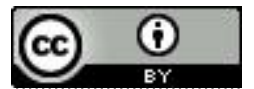




\title{
Hemoglobin adducts in the assessment of potential occupational exposure to acrylamides-three case studies
}

\author{
by Birgit Paulsson, PhD, ${ }^{1}$ Kay-Ole Larsen, MD, ${ }^{2}$ Margareta Törnqvist, PhD ${ }^{1}$
} Paulsson B, Larsen K-0, Törnqvist M. Hemoglobin adducts in the assessment of potential occupational expo-
sure to acrylamides-three case studies. Scand J Work Environ Health 2006;32(2):154-159.

\begin{abstract}
Objectives Workers in three types of occupations with potential exposure to acrylamide were examined for the purpose of excluding or confirming exposure, evaluating actions for reducing exposure, or investigating the possible cause of ill health.

Methods Workers were examined through the measurement of adducts from acrylamide (and $N$-methylolacrylamide) to the $\mathrm{N}$-terminal valines in hemoglobin.

Results The first case concerned workers transporting acrylamide-contaminated waste soil. The measured acrylamide-adduct levels were in the range of the normal background levels (ie, any potential occupational exposure was too low to be detected). The second case included workers handling a sealing product containing acrylamide and $\mathrm{N}$-methylolacrylamide. One worker had an acrylamide-adduct level of $0.3 \mathrm{nmol} / \mathrm{g}$ globin, close to the level at which acrylamide-exposed persons have shown mild reversible symptoms of the peripheral nervous system. After actions to reduce exposure, the adduct levels were still elevated, and, as a precautionary measure, the sealing product was replaced. The third case concerned a man with observed neurotoxic symptoms, working with a sealing product containing acrylamide. This worker had an extremely high acrylamide-adduct level (23 nmol/g globin) (ie, the acrylamide exposure was probably the cause of his ill health). The acrylamide product was replaced, and after 5 months the adduct level had decreased to $2.4 \mathrm{nmol} / \mathrm{g}$ globin, and after another 6 months it was about $0.4 \mathrm{nmol} / \mathrm{g}$ globin.

Conclusions These studies illustrate the usefulness of in vivo dose measurement through the use of hemoglobin adducts for occupational surveillance and as a basis for the health risk assessment of electrophilically reactive compounds.
\end{abstract}

Key terms in vivo dose monitoring; $N$-methylolacrylamide; neurotoxic symptoms; sealing products.

At a tunnel construction site in Sweden in 1997, a grouting agent containing acrylamide and $N$-methylolacrylamide leaked into watercourses and ground water in the surrounding area due to the intense use of the grouting agent and because of heavy water-leakage in the tunnel (1). As a consequence, cattle were poisoned (2), and there was potential exposure of residents in the area. Tunnel workers were exposed to acrylamides, and, in the highest-exposed group, about $40 \%$ exhibited mild neurotoxic symptoms (3). One further consequence of this "scandal" was the emerging concern among employees in other occupational situations that involved the handling of acrylamide as monomers or polymers. This concern led to several studies of potential exposure to acrylamide(s) in occupational settings, with the aim of clarifying whether there was exposure or not. This paper describes three of these studies, undertaken due to concern among the potentially exposed workers.

Acrylamide and $N$-methylolacrylamide are used in the production of polyacrylamides (eg, in grouting and sealing products). Acrylamide is neurotoxic and causes characteristic symptoms of lesions in the peripheral nervous system, such as numbness of the hands and feet, peeling skin, muscular weakness, loss of vibration senses, and ataxic gait $(4,5,6)$. At higher doses the central nervous system may also be affected. Furthermore, acrylamide causes reproductive and genotoxic effects and is classified as probably carcinogenic to humans $(5,6)$.

1 Department of Environmental Chemistry, Stockholm University, Stockholm, Sweden.

2 Department of Occupational Medicine, Aarhus University Hospital, Aarhus, Denmark.

Correspondence to: Dr Margareta Törnqvist, Department of Environmental Chemistry, Stockholm University, S-106 91 Stockholm, Sweden. [E-mail: margareta.tornqvist@mk.su.se] 
The neurotoxic potential of $N$-methylolacrylamide has been shown to be $20-30 \%$ of that of acrylamide (5), and its potency with regard to tumor induction has been estimated to be up to 100 times lower than that of acrylamide [(7) with data from (5)].

Products (adducts) formed in reactions between reactive chemicals and macromolecules (adducts) in the body (eg, hemoglobin) can be used for the biological monitoring of exposure to reactive, harmful agents, but also as a tool for risk assessment (8). Due to the 4-month lifespan of human erythrocytes, hemoglobin adducts give an estimate of the average exposure during the preceding few months. Measured acrylamide-adduct levels in exposed workers have been shown to be correlated with assessed neurotoxic effects $(3,9)$. A no-adverse effect-level (NOAEL) for neurotoxic symptoms in humans with chronic exposure to acrylamide appears to correspond to average acrylamide-adduct levels of 0.3$1 \mathrm{nmol} / \mathrm{g}$ globin [(7) with data from (9)]. NOAEL for numbness or tingling in the feet or legs after 2 months of mixed exposure to acrylamide and $\mathrm{N}$-methylolacrylamide has been estimated to correspond to an adduct level of $0.5 \mathrm{nmol} / \mathrm{g}$ globin (3).

A general background level of acrylamide adducts of about $0.02-0.07 \mathrm{nmol} / \mathrm{g}$ globin has been shown to occur among nonoccupationally exposed persons (3, 10). This background is probably completely or mainly associated with acrylamide in food $(11,12)$. Tobacco smoking has been shown to increase the acrylamideadduct levels by about $0.006 \mathrm{nmol} / \mathrm{g}$ globin per cigarette/day (10). When hemoglobin adducts are used for monitoring low levels of occupational exposure to acrylamide, the contributions from normal background exposure and tobacco smoking have to be compensated for. Tobacco smoking also gives rise to increased hemoglobin-adduct levels from ethylene oxide, a metabolite of ethene (13), a component in tobacco smoke. This increment is estimated to be about $0.008 \mathrm{nmol} / \mathrm{g}$ globin per cigarette/day (14) above a background level of the same adduct (up to $0.035 \mathrm{nmol} / \mathrm{g}$ globin) estimated to originate mainly from endogenous ethene $(15,16)$. Ethylene oxide adducts can thus be used as a biomarker reflecting smoking habits. However, it has to be used with care since ethylene oxide adducts can also be formed as artifacts during the storage of red blood cells (17).

This paper presents three case studies in which the measurement of hemoglobin adducts from acrylamide is used to investigate potential exposure to acrylamide (and $\mathrm{N}$-methylolacrylamide) to assess the outcome of actions to reduce exposure or to search for an external cause of ill health. The first two studies were initiated from respective occupational health services, and the third study from a physician at the hospital where this worker was a patient.

\section{Study population and methods}

Blood samples from workers potentially exposed to acrylamides were collected on one or several occasions, depending on the results from the first measurement. In one of the studies, blood samples from a control person were also collected. In addition, to obtain a larger number of controls, we used reference values of the background acrylamide-adduct levels from nonsmoking control persons in earlier studies [eg, the aforementioned tunnel study (3)]. Two of these samples were also reanalyzed (case study 1 ).

Adduct measurement was performed by the $N$-alkyl Edman method (18) with modifications according to Bergmark (10). The precipitated globin was incubated with pentafluorophenyl isothiocyanate (from Fluka, Buchs, Switzerland). This reagent reacts with the $N$-termini in hemoglobin, which then, if $\mathrm{N}$-alkylated, is detached from the protein as pentafluorophenyl-thiohydantoins ( $N$-alkylvaline-pentafluorophenyl isothiocyanates). The derivative is, after isolation by extraction, analyzed by gas chromatography-tandem mass spectrometry (GC-MS/MS) $(10,18)$. The analysis of adducts from acrylamide and $N$-methylolacrylamide according to this procedure results in an identical derivative, $\mathrm{N}$-(2carbamoylethyl)valine-pentafluorophenyl isothiocyanate. In rodents $N$-methylolacrylamide gives rise to only $20-40 \%$ of the level of this adduct per administered dose, compared with acrylamide (19).

As a biomarker reflecting smoking habits, the adduct from ethylene oxide to $\mathrm{N}$-terminal valine was measured [as $N$-(2-hydroxyethyl)valine-pentafluorophenyl isothiocyanate] (13). Standard compounds for the acrylamide analysis were kindly provided by Dr E Bergmark (10), and ethylene oxide-alkylated globin was prepared as described earlier (20).

\section{Case study 1}

The persons in this case were workers transporting acrylamide-contaminated soil from the aforementioned tunnel construction (1). The soil was transported by trucks to a nearby construction site, where it was dumped and leveled. None of these workers had been in direct contact with the soil, neither had they claimed any symptoms. However, the disclosure of the acrylamide exposure among the tunnel workers (3) resulted in anxiety about possible acrylamide exposure also among these workers. All workers were informed and invited to the investigation, and about half of them chose to participate $(\mathrm{N}=17)$. The work with the soil transport had been going on for a period of about 2 months when the blood sampling was initiated. At the time of the sampling, the workers were interviewed at the health service, and a 
new appointment was offered at the completion of the test results.

The results showed that, in the group of nonsmoking workers $(\mathrm{N}=11)$, the average acrylamide-adduct level was $0.029 \mathrm{nmol} / \mathrm{g}$ globin. This level is in the range of the normal background adduct values for nonsmoking persons, as had been measured for control persons participating in earlier studies. The adduct levels of ethylene oxide $(0.026 \mathrm{nmol} / \mathrm{g}$ globin) were also in agreement with background adduct levels measured for nonsmokers. In the smoking group $(\mathrm{N}=6)$, both the acrylamide-adduct levels and the ethylene-oxide-adduct levels were, as expected, higher, on the average, 0.11 and $0.23 \mathrm{nmol} / \mathrm{g}$ globin, respectively (table 1). Thus the elevated acrylamide-adduct levels in the group of smoking workers could, on the basis of the measured elevated ethylene-oxide-adduct levels, be explained by tobacco smoking $(10,15)$.

In conclusion, a potential occupational exposure to acrylamide, above a general background level, could not be detected. This information assisted in reducing unnecessary anxiety, which was one of the purposes of this study.

\section{Case study 2}

The second case involved four workers (including one control) employed in a glass-processing industry producing windows. All of the workers were nonsmokers, but two of them were snuff users. The particular work situation involved sealing double-glass windows with an interlayer product that was identical to the grouting product used in the aforementioned tunnel construction (1). The sealing work was carried out $2-5$ hours per day in a special room with increased ventilation. During the work, protective clothes, face shields, rubber gloves, and rubber boots were used, and, in certain operations that were suspected to cause increased exposure via inhalation, also gas masks were worn. Despite the protective precautions and the fact that the workers had not claimed any work-related symptoms, questions were raised concerning potential acrylamide exposure and possible health risks. Could a presumed exposure be detectable as increased acrylamide-adduct levels in hemoglobin? If so, how was the exposure related to the occupational exposure limit (OEL) for acrylamide? Was there any risk of health effects? Could the exposure be lowered if reducing actions were introduced? Blood samples from workers who were dealing with the acrylamide-containing product and from one worker with other tasks were collected on two occasions with a 1year interval.

The analysis of the first blood samples showed that the worker who most frequently worked with the interlayer product (A) had an adduct level of $0.31 \mathrm{nmol} / \mathrm{g}$ globin, which was almost 10-fold higher than the adduct level of the nonsmoking control person $(0.035$ $\mathrm{nmol} / \mathrm{g}$ globin). Another worker (B), who was only sporadically working with the interlayer product, showed an acrylamide-adduct level of $0.094 \mathrm{nmol} / \mathrm{g}$ globin (table 1). On the basis of these results, new special chemical protection suits were introduced, together with more rigorous routines for the use of personal protective equipment.

The second blood collection was performed more than 4 months after the introduction of new routines (1 year after the first sample collection). Blood was collected from one of the workers (A) earlier studied and from a worker $(\mathrm{C})$ who had worked with the interlayer product only during this last year. The analysis showed acrylamide-adduct levels of 0.20 and $0.19 \mathrm{nmol} / \mathrm{g}$ globin for these two workers, still an elevated level compared with that of the nonsmoking control person (table 1). A background adduct level of $0.2 \mathrm{nmol} / \mathrm{g}$ globin

Table 1. Levels of hemoglogin adducts from acrylamide and ethylene oxide in blood from workers with potential exposure to acrylamide.

\begin{tabular}{|c|c|c|c|c|c|}
\hline \multirow[t]{2}{*}{ Type of work } & \multirow[t]{2}{*}{ Subject(s) } & \multicolumn{2}{|c|}{$\begin{array}{l}\text { Acrylamide-adduct level a } \\
\text { (nmol/g globin) }\end{array}$} & \multicolumn{2}{|c|}{$\begin{array}{l}\text { Ethylene-oxide-adduct level a } \\
\text { (nmol/g globin) }\end{array}$} \\
\hline & & Mean & SD & Mean & SD \\
\hline \multirow[t]{3}{*}{ Case study 1 (transport of soil) } & Nonsmoking workers $(\mathrm{N}=11)$ & 0.029 & 0.008 & 0.026 & 0.013 \\
\hline & Smoking workers $(\mathrm{N}=6)$ & 0.11 & 0.036 & 0.23 & 0.112 \\
\hline & Nonsmoking controls ${ }^{b}(\mathrm{~N}=2)$ & 0.023 & $\cdot$ & 0.024 & $\cdot$ \\
\hline \multirow[t]{5}{*}{ Case study 2 (glass work, nonsmokers) } & Worker A, year I & 0.31 & . & 0.017 & . \\
\hline & Worker B ${ }^{c}$, year I & 0.094 & . & 0.023 & . \\
\hline & Worker A, year II & 0.20 & . & .. & . \\
\hline & Worker C ${ }^{\mathrm{c}}$, year II & 0.19 & . & $\because$ & . \\
\hline & Control, year I (re-analyzed year II) & 0.035 & . & 0.021 & . \\
\hline \multirow[t]{3}{*}{ Case study 3 (sealing work, smoker) } & Worker A, 9 months after high exposure event & 23 & . & .. & . \\
\hline & Worker A, 5 months after product replacement & 2.3 & . & .. & . \\
\hline & Worker A, 1 year after product replacement & 0.41 & . & $\sim 0.4$ & . \\
\hline
\end{tabular}

a Reported adduct levels for cases 2 and 3 are mean values from 2-4 analyses per sample.

b Re-analysis of blood samples from an earlier study.

c Snuff user. 
is not unusual for smokers. However, these workers were nonsmokers, and this status was also confirmed by the analysis of ethylene oxide adducts. Therefore, tobacco smoking could be excluded as a contributor to the elevated acrylamide-adduct level. Snuff use ("normal" consumption) is estimated to give a contribution of about $0.02 \mathrm{nmol} / \mathrm{g}$ globin (21) to the acrylamide-adduct level, and this level could not explain the elevated acrylamide-adduct levels of the two snuff-using workers (B and C). Thus the measured incremental acrylamideadduct levels were, in all probability, due to occupational exposure to acrylamides.

The acrylamide exposure in this case concerned a product that has earlier been shown to contain around 4-5\% acrylamide and about $30 \% \mathrm{~N}$-methylolacrylamide (3). $\mathrm{N}$-methylolacrylamide exposure contributes to only about $30 \%$ of the measured adduct levels when compared with acrylamide per exposure dose (19). Therefore, about half of the measured adducts in this case was estimated to originate from acrylamide exposure. The Swedish occupational exposure level for acrylamide is $0.03 \mathrm{mg} / \mathrm{m}^{3}$ air (22). Exposure to acrylamide at such an air concentration has been estimated to give rise to an incremental acrylamide-adduct level of about $0.05 \mathrm{nmol} / \mathrm{g}$ globin (above the normal background level) (7). In this case, the verified exposure probably exceeded the occupational exposure limit for acrylamide in air. However, the measured adduct level of around $0.2 \mathrm{nmol} / \mathrm{g}$ globin that originated from exposure to this actual product would correspond to a negligibly low risk of impairment of the peripheral nervous system according to the proposed NOAEL value $(0.5 \mathrm{nmol} / \mathrm{g}$ globin $)$ already mentioned (3). As a consequence of this study, the acrylamide-containing interlayer product used in the window-manufacturing was replaced with another product as a means of precaution.

\section{Case study 3}

The third case concerned a man (smoker) employed at a firm of contractors. His work consisted of repairing concrete constructions using an acrylamide-containing sealing product. At work he wore ordinary workclothes and protective gloves but no respiratory protection equipment. He had worked with these tasks for more than 15 years, and for long periods he had suffered from dizziness and ataxia leading to an unsteady gait, which from time to time had forced him to stay home from work. At a former visit to a neurological clinic, the diagnosis was multiple sclerosis, later altered to encephalopatia causa incerta (brain disease with an uncertain cause). After some repair work inside a poorly ventilated container, he developed the following acute severe symptoms: dizziness, unsteady and straddle-legged gait, and paresthesia in the fingers of both hands. After this incident he was referred to a clinic for occupational medicine, where he received a diagnosis of medium polyneuropathy, effects on the sensory and motor nerve fibers and "abnormal visual-evoked potential", and central demyelinization (4). At this clinic, his symptoms were related to those of the Swedish tunnel workers exposed to acrylamides (3), and an investigation of suspected acrylamide exposure was initiated.

The first blood sample was collected 9 months after the aforementioned repair work in the container. During the 4 months preceding this blood collection, no such exceptional high-exposure incident had been reported. The analysis showed a very high acrylamideadduct level (23 nmol/g globin). This adduct level is compatible with what was reported in a study of acrylamide workers in China (23), where most of the workers that had adduct levels about and above $20 \mathrm{nmol} / \mathrm{g}$ globin suffered from neurotoxic symptoms. Thus the conclusion was that this man's work conditions implied very high exposure to acrylamide and that the high exposure was probably the cause of his illness. It was decided to replace the acrylamide product. The replacement product was based on 2-hydroxyethyl-metacrylate (2-HEMA), a compound that is not reported to be neurotoxic.

Five months after the replacement a second blood sample was collected. The analysis showed a 10 times lower adduct level ( $2.4 \mathrm{nmol} / \mathrm{g}$ globin) (table 1$)$, which, however, still implied a high risk of impairment of the peripheral nervous system, according to the estimated NOAEL values $(3,7)$. Measurements of nerve conduction velocity a month before this blood sampling showed polyneuropathy in the legs and forearms (4).

To investigate whether the replacement product could be a source of the still elevated acrylamide-adduct level, an experiment was performed with incubation of human blood with the product (1-hour incubation at $37^{\circ} \mathrm{C}$ with a 2-hydroxyethyl methacrylate concentration of $0.2 \mathrm{mM}$ ). This sample was then prepared and analyzed according to the procedure described for blood samples in the methods section. The analysis revealed a peak in the GC-MS/MS chromatogram with identical characteristics to that of the acrylamide adduct. The intensity of the peak from the replacement product corresponded to a few percent of the adduct level obtained from blood incubated by an equal dose of acrylamide [as described by Paulsson et al (24)]. This finding indicates that a small fraction of the measured acrylamide adduct level in the second blood sample from the worker derived from exposure to the new sealing product. However, the formation of adducts from the 2hydroxyethyl methacrylate-based product must be investigated further (eg, with regard to precursor).

The third sample, collected 1 year after the product replacement, showed an adduct level of $0.41 \mathrm{nmol} / \mathrm{g}$ 
globin, which is still a high adduct level even for a smoker. The studied person stated a cigarette consumption of about 20 cigarettes/day, which would render an acrylamide-adduct level of up to $0.2 \mathrm{nmol} / \mathrm{g}$ globin (10). Measurement of ethylene oxide adducts showed an adduct level that was about 20 times higher than that of the nonsmoking controls, indicating twice as high cigarette consumption than was stated.

In a recent study of people from the general population acrylamide-adduct levels of up to $0.5 \mathrm{nmol} / \mathrm{g}$ globin were found in smokers with an estimated high acrylamide intake from their diet (25). Therefore, a combination of lifestyle factors may explain the adduct level measured in the third blood sample.

One year after the collection of the third blood sample, the worker still exhibited neurotoxic symptoms such as impaired coordination, ataxia, and an unsteady gait. The nerve conduction velocity test again showed polyneuropathy in the legs and forearms. This finding showed that the reduced exposure to acrylamide did not eliminate the worker's ill health. The high exposure to acrylamide during a long period of his worklife $(>15$ years) had probably led to irreversible nerve damage, and the verified polyneuropathy strongly contributed to this damage. He was then unable to continue to work.

\section{Discussion}

Exposure to acrylamide may occur through inhalation, dermal uptake, or ingestion. Therefore, it is not possible to estimate the total uptake strictly from measurements of air concentrations (no measurements of the air concentrations were made for the reported cases). When acrylamide adducts are measured in hemoglobin, the total uptake from all routes is monitored.

To be able to draw conclusions from measured hemoglobin-adduct levels at low occupational exposure to acrylamide, information about the smoking habits of the workers is important. The contribution from smoking could be estimated by an independent marker (eg, ethylene oxide adducts), as has been done in this study. However, the uptake of acrylamide from snuff (21), which also has to be considered, is not reflected by ethylene oxide adducts. Therefore, another marker [eg, acrylonitrile (26)] could be a better alternative.

In the studies $(3,10,23)$, of acrylamide exposure referred to in this report, the analyses have been performed using procedures (sample preparation and analysis), standards (identification and calibration), and instrumentation (GC-MS/MS) identical to those used with the current case studies. The background values and smoking-related increments inferred from these studies can thus be used for comparison and in the discussion of the actual results. New data on background acrylamide-adduct levels, published $(25,27)$ since these case studies, are in agreement with the data referred to and obtained in this report.

In the current three case studies, hemoglobin-adduct measurement was used to confirm or exclude exposure to acrylamides. The first case exemplified how verification of negligible exposure can assist to counteract unnecessary anxiety. In the second case, an exposure was detected by adduct levels of $0.1-0.3 \mathrm{nmol} / \mathrm{g}$ globin in nonsmoking workers (probably corresponding to an uptake exceeding the occupational exposure limit for acrylamide in air). No perceived symptoms were reported, and the lack of symptoms is in accordance with the proposed NOAEL value for acrylamide exposure of 0.3-1 $\mathrm{nmol} / \mathrm{g}$ globin for light reversible symptoms of the peripheral nervous system $(3,7)$. In the third case, hemoglobin-adduct measurement was used to find an external cause of symptoms of ill health. Severe neurological symptoms were observed at an exposure level corresponding to extremely high average acrylamide-adduct levels (above $20 \mathrm{nmol} / \mathrm{g}$ globin) with probably occasionally even higher exposure levels in the past. Such high adduct levels correspond to an estimated daily intake of about $0.8 \mathrm{mg}$ acrylamide/ $\mathrm{kg}$ body weight [parameter values from Calleman (28)], which exceeds the NOAEL of $0.5 \mathrm{mg} / \mathrm{kg}$ body weight per day proposed by the World Health Organization (29) for acrylamide neuropathy in humans.

\section{Acknowledgments}

The authors wish to thank Dr Bernt Wikström and Mr Jörgen Rangvin for their assistance in realizing this study. Mr Ioannis Athanassiadis is acknowledged for his technical assistance with the mass spectrometry analysis and Professor Lars Hagmar and the late Professor Emeritus Lars Ehrenberg for their critical review of the manuscript.

The studies were supported economically by the Swedish Council for Work Life Research, the Swedish National Institute for Working Life, and the Cancer and Allergy Foundation.

\section{References}

1. The Tunnel Commission. Kring Hallandsåsen [About Hallandsåsen]. Stockholm: Swedish Ministry of the Environment; 1998. SOU 1998:60.

2. Godin AC, Bengtsson B, Niskanen R, Tareke E, Törnqvist M, Forslund K. Acrylamide and N-methylolacrylamide poisoning in a herd of Charolais crossbreed cattle. Vet Rec. 
2002;151(24):724-8.

3. Hagmar L, Törnqvist M, Nordander C, Rosén I, Bruze M, Kautiainen A, et al. Health effects of occupational exposure to acrylamide using hemoglobin adducts as biomarkers of internal dose. Scand J Work Environ Health. 2001;27(4):219-26.

4. Gjerløff T, Elsborg H, Bonde JPE. Svaer kronisk acrylamidintoksikation [Severe chronic acrylamide intoxication]. J Danish Med Assoc. 2001;163:4204-5.

5. International Agency for Research on Cancer (IARC). Some industrial chemicals. Lyon: IARC; 1994. IARC monographs on the evaluation of carcinogen risk to humans, vol 60. p 389441.

6. European Commission (EC). European Union Risk Assessment Report, Acrylamide, Risk Assessment. Luxembourg: Office for Official Publications of the European Communities; 2002.

7. Törnqvist M, Bergmark E, Ehrenberg L, Granath F. Riskbedömning av akrylamid [Risk assessment of acrylamide] [English summary]. Stockholm: National Chemicals Inspectorate; 1998. PM KEMI nr 7-98.

8. Törnqvist M, Fred C, Haglund J, Helleberg H, Paulsson B, Rydberg P. Protein adducts: Quantitative and qualitative aspects of their formation, analysis and applications. J Chromatogr B. 2002;778(1-2):279-308.

9. Calleman C-J, Wu Y, Tian G, Bergmark E, Zhang S, Deng H et al. Relationships between biomarkers of exposure and neurological effects in a group of workers exposed to acrylamide. Toxicol Appl Pharmacol. 1994;126(2):361-71.

10. Bergmark E. Hemoglobin adducts of acrylamide and acrylonitrile in laboratory workers, smokers, and nonsmokers. Chem Res Toxicol. 1997;10(1):78-84.

11. Tareke E, Rydberg P, Karlsson P, Eriksson S, Törnqvist M. Acrylamide: a cooking carcinogen? Chem Res Toxicol. 2000;13(6):517-22.

12. Tareke E, Rydberg P, Karlsson P, Eriksson S, Törnqvist M. Analysis of acrylamide, a carcinogen formed in heated foodstuffs. J Agric Food Chem. 2002;50(17):4998-5006.

13. Törnqvist M, Osterman-Golkar S, Kautiainen A, Jensen S, Farmer PB, Ehrenberg L. Tissue doses of ethylene oxide in cigarette smokers determined from adducts levels in hemoglobin. Carcinogenesis. 1986;7(9):1519-21.

14. Törnqvist M. Monitoring and cancer risk assessment of carcinogens, particularly alkenes in urban air [dissertation]. Stockholm: Stockholm University; 1989.

15. Törnqvist M, Kautiainen A. Adducted proteins for identification of endogenous electrophiles. Environ Health Perspect. 1992;99:39-44.

16. Filser JG, Denk B, Törnqvist M, Kessler W, Ehrenberg L. Pharmacokinetics of ethylene in man; body burden with ethylene oxide and hydroxyethylation of hemoglobin due to endogenous and environmental ethylene. Arch Toxicol. 1992;66(3):157-63.
17. Törnqvist M. Formation of reactive species that lead to hemoglobin adducts during storage of blood samples. Carcinogenesis. 1990;11(1):51-4.

18. Törnqvist M, Mowrer J, Jensen S, Ehrenberg L. Monitoring of environmental cancer initiators through hemoglobin adducts by a modified Edman degradation method. Anal Biochem. 1986;154(1):255-66.

19. Paulsson B, Grawé J, Törnqvist M. Hemoglobin adducts and micronucleus frequencies in mouse and rat after acrylamide or N-methylolacrylamide treatment. Mutat Res. 2002;516(12):101-11.

20. Törnqvist M. Epoxide adducts to N-terminal valine of hemoglobin. In: Everse J, Vandegriff KD, Winslow RW, editors. Methods in enzymology, vol 231. San Diego (CA): Academic Press; 1994. p 650-7.

21. Licea Pérez H. In vivo dosimetry of some important industrial chemicals by measurement of their reaction products with hemoglobin [dissertation]. Stockholm: Stockholm University; 2000.

22. Arbetarskyddsstyrelsen (ASF). Occupational exposure limit values and measures against air contaminants. Stockholm: Arbetarskyddsstyrelsens författningssamling; 2000. ASF 2000:3

23. Bergmark E, Calleman CJ, He F, Costa LG. Determination of hemoglobin adducts in humans occupationally exposed to acrylamide. Toxicol Appl Pharmacol. 1993(1);120:45-54.

24. Paulsson B, Rannug A, Henderson AP, Golding BT, Törnqvist $\mathrm{M}$, Warholm M. In vitro studies of the influence of glutathione transferases and epoxide hydrolase on the detoxification of acrylamide and glycidamide in blood. Mutat Res. 2005;580(1-2): 53-60.

25. Hagmar L, Wirfält E, Paulsson B, Törnqvist M. Differences in hemoglobin adduct levels of acrylamide in the general population with respect to dietary intake, smoking habits and gender. Mutat Res. 2005;580(1-2):157-67.

26. Licea Pérez H, Segerbäck D, Osterman-Golkar S. Adducts of acrylonitrile with hemoglobin in nonsmokers and in participants in a smoking cessation program. Chem Res Toxicol. 1999;12(10):869-73.

27. Schettgen T, Rossbach B, Kütting B, Letzel S. Drexler H, Angerer J. Determination of haemoglobin adducts of acrylamide in smoking and non-smoking persons of the general population. Int J Hyg Environ Health. 2004;207(6):531-39.

28. Calleman CJ. The metabolism and pharmacokinetics of acrylamide: implications for mechanisms of toxicity and human risk. Drug Metab Rev. 1996;28(4):527-90.

29. World Health Organization (WHO). Health Implications of Acrylamide in Food: report of a joint FAO/WHO consultation. Geneva: Department of protection of the Human Environment, WHO; 2002.

Received for publication: 28 March 2003 